\title{
Early postnatal stress and the serotonergic system Mitsuhiro Yoshioka
}

\author{
Address: Department of Neuropharmacology, Hokkaido University, Graduate School of Medicine, Sapporo, Japan \\ from International Society on Brain and Behaviour: 3rd International Congress on Brain and Behaviour \\ Thessaloniki, Greece. 28 November - 2 December 2007 \\ Published: 17 April 2008 \\ Annals of General Psychiatry 2008, 7(Suppl I):S23 doi:I0.1 I86/I744-859X-7-SI-S23
}

This abstract is available from: http://www.annals-general-psychiatry.com/content/7/SI/S23

(c) 2008 Yoshioka; licensee BioMed Central Ltd.

The aim of the present study was to assess whether traumatic events during the early postnatal period would affect the rat brain development of the serotonergic system underlying regulation of emotional expressions. Rats that had received aversive stimuli foot shock (FS) at the postnatal period of the second week (2W-FS), but not the third week (3W-FS), markedly reduced fear-related freezing behavior during exposure to contextual fear conditioning (CFC), at the post-adolescent period (10-12 week old). This anxiolytic behavior observed in $2 \mathrm{~W}$-FS was mimicked by electrolytic lesion of the median raphe nuclei, from which the major serotonergic projections to the hippocampus arise. In 3W-FS, as well as non-FS controls, synaptic transmission in the hippocampal CA1 field was suppressed by the serotonin $(5-\mathrm{HT})_{1 \mathrm{~A}}$ receptor agonist. This synaptic inhibition was not found in $2 \mathrm{~W}-\mathrm{FS}$. These findings suggest that aversive stress exposed at the early postnatal period might affect the serotonergic development, thereby emotional responses to the post-adolescent fear stimuli. In other words, the "critical developmental period" appears to exist for the serotonergic system involved in emotional expressions, which is attributable to the lifelong susceptibility to emotional stimuli. 